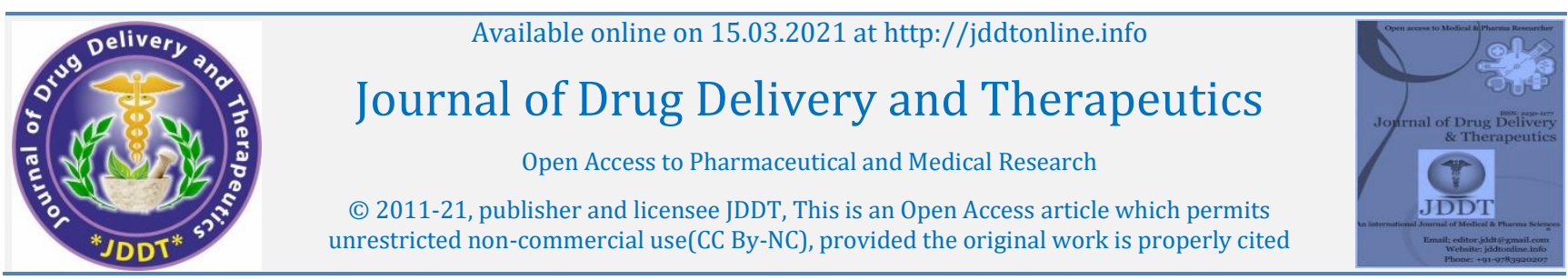

(C) 2011-21, publisher and licensee JDDT, This is an Open Access article which permits Open Access Full Text Article

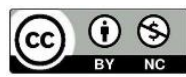

Research Article

\title{
Efficacy of Whole-Body versus Lesional Application of Permethrin Cream for Scabies Treatment: A Quasi-Experimental Study
}

\author{
Sungkar, Saleha1; Haswinzky, Rose A.1; Dwinastiti, Yasmine A.1; Wardhana, Aji W.1; Irmawati, Fanny P.1; \\ Kekalih, Aria2; (D) Widaty. Sandra ${ }^{3 *}$
}

${ }^{1}$ Department of Parasitology Faculty of Medicine Universitas Indonesia, Jakarta, Indonesia

${ }^{2}$ Department of Community Medicine Faculty of Medicine Universitas Indonesia, Jakarta, Indonesia

${ }^{3}$ Department of Dermatology Venereology Faculty of Medicine Universitas Indonesia-dr. Cipto Mangunkusumo National Central General Hospital, Jakarta, Indonesia

\section{Article Info:}

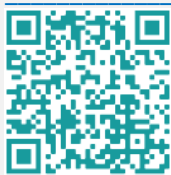

\section{Article History:}

Received 19 Jan 2021;

Review Completed 24 Feb 2021

Accepted 05 March 2021;

Available online 15 March 2021

\section{Cite this article as:}

Sungkar S, Haswinzky RA, Dwinastiti, YA, Wardhana, AW, Irmawati FP, Kekalih A, Widaty S, Efficacy of Whole-Body versus Lesional Application of Permethrin Cream for Scabies Treatment: A QuasiExperimental Study, Journal of Drug Delivery and Therapeutics. 2021; 11(2):68-71

DOI: http://dx.doi.org/10.22270/jddt.v11i2.4778

\section{*Address for Correspondence:}

S. Widaty, MD, PhD, Department of Dermatology Venereology Faculty of Medicine Universitas Indonesia-dr. Cipto Mangunkusumo National Central General Hospital, Jakarta, Indonesia.

ORCID ID: https://orcid.org/0000-0002-7347-8959

\section{Abstract}

Objective: The study aims to evaluate the efficacy of whole-body versus lesional application of $5 \%$ permethrin cream for scabies eradication.

Design: This quasi-experimental study was conducted on September-October 2018 at boarding schools in Bogor and East Jakarta, Indonesia. Subjects were randomized into two groups, 51 students each.

Interventions: The first group received a whole-body application while the second group received lesional application of 5\% permethrin cream. Evaluation was performed after 7 and 28 days.

Main outcome measures: Proportion of lesions cured following the intervention

Results: The prevalence of scabies was $41 \%$ and $33 \%$ at the boarding schools in Bogor and East Jakarta, respectively. Subjects from both groups had similar lesion distributions at baseline ( $p>0.05$ ). Following intervention, the number of lesions reduced significantly $(p<0.001)$ and both treatments were equally effective in treating scabies with $84.6 \%$ vs 91.5\% cure rate [Relative Risk (RR) 1.8(0.6-5.0); $p>0.05$ ].

Conclusion: Lesional application of 5\% permethrin is proven to be equally effective in treating scabies with higher cure rate. This method shows advantage for scabies treatment In addition to reduce the unwanted side effects, it is more cost-effective and convenient. Further studies with larger sample size and randomized controlled trial design are warranted.

Keywords: scabies, permethrin, whole-body application, lesional application, cure rate

\section{INTRODUCTION}

Scabies is a common skin disease affecting primarily people who live in an overcrowded area with poor hygiene and low socioeconomic status. Therefore, it is most commonly found in boarding schools, orphanages, and prisons. The prevalence of scabies infestation reached $78 \%$ at a boarding school in Jakarta, Indonesia.1,2 It manifests as nocturnal pruritus accompanied by various skin lesions, such as papules, vesicles, pustules, and excoriation. The webbed spaces of fingers, wrist, axilla, areola mammae, inframammary fold, umbilicus, buttocks, penis, and scrotum are the most commonly affected areas. Fever and lymphadenopathy indicate a secondary bacterial infection. ${ }^{3}$ Those symptoms might potentially impair daily activities, reduce concentration, and affect quality of life of the patients.
The treatment of choice for scabies is $5 \%$ permethrin cream, which is applied on the skin from neck to toe. It should be left on the skin for ten hours before rinsing it off. The cream can be reapplied after a one-week interval to eliminate the residual mites and eggs. ${ }^{4}$ The application of permethrin may produce unpleasant side effects, such as stickiness, itchiness, burning sensation, and irritant contact dermatitis.5,6 Thus, there has been a consideration to treat scabies by applying permethrin only on visible skin lesions and instructing the patient to take a shower twice daily with soap. This method was anticipated to eradicate the mites within the stratum corneum and the remaining mites surviving on the skin surface are expected to be washed away during the shower. If any subclinical lesions appear, they will be treated eventually the following week.? 


\section{Sungkar et al}

This study aims to evaluate the efficacy of whole-body versus lesional application of $5 \%$ permethrin cream for scabies treatment.

\section{MATERIALS AND METHODS}

\section{Study Design}

This is a quasi-experimental study, which was preceded by a cross-sectional prevalence survey to obtain study subjects. It was conducted from September to October 2018 at two boarding schools in Bogor (School X) consisting of 160 students and East Jakarta (School Y) consisting of 184 students. All subjects are male students, agreed to be treated and evaluated three times at the baseline, 7 days and 28 days following treatment. Subjects with crusted scabies were excluded since the cream must be applied every 2-3 days for 1-2 weeks and not after a one-week interval.

\section{Sample Size}

An initial screening was conducted on all students to obtain scabies patients. Based on the sample size calculation, the prevalence survey needs a minimum amount of 323 subjects. Then, the sample size for efficacy study is calculated and a total of 46 subjects was needed for each group. To anticipate drop out, $10 \%$ was taken into account for sample size calculation. Hence, 51 subjects were recruited.

\section{Data Collection}

On the first day, all students and teachers were given health education session focusing on scabies and a healthy lifestyle. The students were taught how to take a proper shower with soap and reminded not to share soap, towel, clothes, and other personal belongings. All students were also explained about the study, in which the dermatologists would undergo a dermatological examination to diagnose and treat scabies. The diagnosis was established clinically by 2 out of 4 of the cardinal criteria, which are nocturnal pruritus, similar symptoms in roommates, presence of mites, and presence of mites' burrow. ${ }^{5}$

The subjects were given treatment according to their assigned groups. The first group received whole-body application of $5 \%$ permethrin cream, whereas the second group received lesional application. The application of permethrin was performed by the investigators to ensure that it was applied correctly. The applied cream was left for ten hours and if the cream was washed off e.g. after ablution or handwashing, the students were asked to reapply the cream on the lesion. After ten hours, the students were instructed to take a shower with soap. If the students felt any discomfort after permethrin application, they were asked to report to the investigators. The application of permethrin was repeated after a one-week interval by the investigators.

The result of treatment was evaluated on week-1 and week-4 by observing the lesions. The cured criteria were no new lesions, all previous lesions flattened and became hyperpigmented. The investigators who evaluated and assessed the cure rate were blinded. The subjects cannot be blinded because of the different method of application.

Data were analyzed using IBM SPSS statistics version 20. Chisquare test or Fischer's exact test (if the chi-square test's requirements were not met) was performed to assess the association between the cure rate and scabies infestation. The cure rate was obtained by calculating the number of
Journal of Drug Delivery \& Therapeutics. 2021; 11(2):68-71 subjects cured against the total number of subjects. The association between variables was determined by relative risk (RR) and 95\% confidence interval (CI). P-value $<0.05$ was considered as statistically significant.

\section{Ethics}

The students were less than 18 years old (12-14 years), thus the informed consent was obtained from the teacher (school principal). The Ethics Committee of the Faculty of Medicine Universitas Indonesia had approved this study (ethical clearance ID: 0855/UN2.F1/ETIK/2018).

\section{RESULTS}

A total of 344 subjects were recruited from two boarding schools (160 subjects from school X and 184 subjects from school Y). The prevalence rates of scabies were $41 \%$ $(65 / 160)$ in school $X$ and $33 \%(59 / 184)$ in school Y. All scabies cases were included in the study. The selection of study participants was shown in Figure 1.

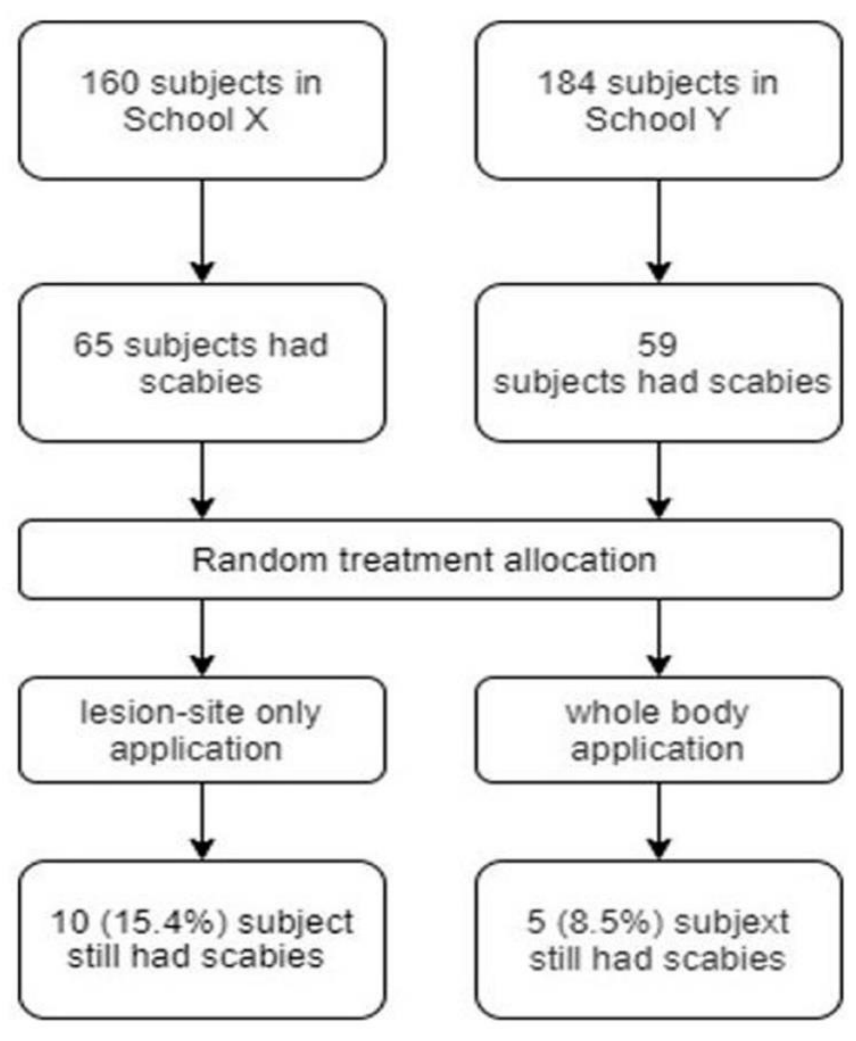

Figure 1: Flow diagram of the study

Table 1 shows that all subjects from both groups had similar lesion distributions at baseline ( $p>0.05)$, except for armpit, umbilicus, scrotum, and penis $(\mathrm{p}<0.05)$. Following intervention, there were no significant differences between the lesion distributions in both groups at any locations. Some areas were completely lesion-free following the intervention, such as nipple and penis. There was no significant difference of the cure rate between the whole-body and lesional application [RR 1.8(0.6-5.0)]. A total 55 subjects $(84.6 \%)$ were cured in the whole-body application group compared to 54 subjects $(91.5 \%)$ cured in the lesional application group. 
Table 1: Distribution of scabies lesions pre- and post-intervention

\begin{tabular}{lccccccc}
\hline \multicolumn{1}{c}{ Body sites } & \multicolumn{2}{c}{$\begin{array}{c}\text { Pre-intervention } \\
\text { Whole-body } \\
\text { application }\end{array}$} & $\begin{array}{c}\text { Lesional } \\
\text { application }\end{array}$ & & $\begin{array}{c}\text { Post-intervention } \\
\text { Whole-body } \\
\text { application }\end{array}$ & $\begin{array}{c}\mathbf{p}^{\mathbf{b}} \\
\text { Lesional } \\
\text { application }\end{array}$ & RR (95\%CI) \\
\hline Finger web & $43(66.2 \%)$ & $35(59.3 \%)$ & 0.432 & $4(6.2 \%)$ & $3(5.1 \%)$ & 0.797 & $1.2(0.2-5.7)$ \\
Wrist & $27(41.5 \%)$ & $23(39.0 \%)$ & 0.772 & $3(4.6 \%)$ & $2(3.4 \%)$ & 0.729 & $1.3(0.2-7.8)$ \\
Elbow & $17(26.2 \%)$ & $12(20.3 \%)$ & 0.445 & $2(3.1 \%)$ & $1(1.7 \%)$ & 0.617 & $1.8(0.1-19.5)$ \\
Armpit & $19(29.2 \%)$ & $4(6.8 \%)$ & $0.001^{*}$ & $2(3.1 \%)$ & $0(0.0 \%)$ & 0.174 & - \\
Umbilicus & $20(30.8 \%)$ & $9(15.3 \%)$ & 0.042 & $1(1.5 \%)$ & $0(0.0 \%)$ & 0.339 & - \\
Gluteal & $22(33.8 \%)$ & $21(35.6 \%)$ & 0.838 & $3(4.6 \%)$ & $2(3.4 \%)$ & 0.729 & $1.3(0.2-7.8)$ \\
Nipple & $3(4.6 \%)$ & $5(8.5 \%)$ & 0.382 & $0(0 \%)$ & $0(0.0 \%)$ & 1.000 & - \\
Scrotum & $10(15.4 \%)$ & $20(33.9 \%)$ & $0.016 *$ & $0(0 \%)$ & $2(3.4 \%)$ & 0.135 & - \\
Penis & $9(13.8 \%)$ & $20(33.9 \%)$ & $0.008 *$ & $0(0 \%)$ & $0(0.0 \%)$ & 1.000 & - \\
Total subjects & $\mathbf{6 5 ( 1 0 0 \% )}$ & $\mathbf{5 9 ( 1 0 0 \% )}$ & $\mathbf{0 . 7 2 9}$ & $\mathbf{1 0}(\mathbf{1 5 . 4 \% )}$ & $\mathbf{5 ( 8 . 5 \% )}$ & $\mathbf{0 . 2 3 9}$ & $\mathbf{1 . 8}(\mathbf{0 . 6}-5.0)$ \\
\hline
\end{tabular}

Table 2 shows that the number of scabies lesions decreased significantly on all body sites following interventions, both whole-body and lesional application $(\mathrm{p}<0.001)$. However, several body sites could not be analyzed since there were no lesions left following intervention.

Table 2: Analysis of scabies lesions improvement following intervention

\begin{tabular}{|c|c|c|c|c|c|c|}
\hline \multirow[t]{2}{*}{ Body sites } & \multicolumn{2}{|c|}{ Whole-body application } & \multicolumn{4}{|c|}{ Lesional application } \\
\hline & Pre & Post & $\mathbf{p}^{\mathbf{a}}$ & Pre & Post & $\mathbf{p}^{\mathbf{a}}$ \\
\hline Finger Web & $43(66.2 \%)$ & $4(6.2 \%)$ & $<0.001^{*}$ & $35(59.3 \%)$ & $3(5.1 \%)$ & $<0.001^{*}$ \\
\hline Wrist & $27(41.5 \%)$ & $3(4.6 \%)$ & $<0.001^{*}$ & $23(39.0 \%)$ & $2(3.4 \%)$ & $<0.001^{*}$ \\
\hline Elbow & $17(26.2 \%)$ & $2(3.1 \%)$ & $<0.001^{*}$ & $12(20.3 \%)$ & $1(1.7 \%)$ & $<0.001^{*}$ \\
\hline Armpit & $19(29.2 \%)$ & $2(3.1 \%)$ & $<0.001^{*}$ & $4(6.8 \%)$ & $0(0 \%)$ & NA \\
\hline Umbilicus & $20(30.8 \%)$ & $1(1.5 \%)$ & $<0.001^{*}$ & $9(15.3 \%)$ & $0(0 \%)$ & NA \\
\hline Gluteal area & $22(33.8 \%)$ & $3(4.6 \%)$ & $<0.001^{*}$ & $21(35.6 \%)$ & $2(3.4 \%)$ & $<0.001^{*}$ \\
\hline Nipple & $3(4.6 \%)$ & $0(0 \%)$ & NA & $5(8.5 \%)$ & $0(0.0 \%)$ & NA \\
\hline Scrotum & $10(15.4 \%)$ & $0(0 \%)$ & NA & $20(33.9 \%)$ & $2(3.4 \%)$ & $<0.001^{*}$ \\
\hline Penis & $9(13.8 \%)$ & $0(0 \%)$ & NA & $20(33.9 \%)$ & $0(0 \%)$ & NA \\
\hline
\end{tabular}

aMcNemar test *statistically significant

\section{DISCUSSION}

Indonesia is a tropical country with high burden of scabies cases, indicated with disability-adjusted life years (DALYs) of 153.86 in $2015.8,9$ The treatment of scabies is by applying permethrin $5 \%$ to all body regions except face and neck and leaving it for 8-12 hours before taking a bath to wash it off. Whole-body application of scabicide aims to eradicate all mites, including subclinical lesions which are not visible during dermatological examination. The treatment is typically repeated after a one-week interval until the patient is completely cured.13 The long duration of skin exposure to permethrin may elicit uncomfortable side effects, such as burning sensation and irritant contact dermatitis. ${ }^{5,6}$

To reduce the side effects, we conducted a study of lesional application of $5 \%$ permethrin cream accompanied by shower twice daily to ensure eradication of all mites by soap and water. The other group also practices twice-daily shower. The study found that whole-body and lesional applications of permethrin cream were equally effective to treat scabies. There were no statistically significant differences of cure rates between both groups (84.6\% vs $91.5 \%$; p>0.05). Further analysis showed that both treatments yielded similar clinical improvement on all body sites $(\mathrm{p}<0.001)$. Chhaiya et al. ${ }^{14}$ reported similar effectiveness of permethrin in treating scabies to ivermectin in patients with uncomplicated scabies.

This study showed that most lesions were found on the finger webs and wrists. Result of this study showed that the lesional application group had no lesions left at nipple and scrotum post-intervention. These missed lesions may serve as the source of an unresolved infection. It emphasizes the importance of a thorough briefing and health education as subjects are usually reluctant to expose these sites as it concerns their privacy. A detailed examination of these 


\section{Sungkar et al}

sensitive regions has to be performed to ensure complete eradication and successful treatment of scabies infestation. In daily practice, permethrin application may require another person's help since some body sites were hardly reached when self-applied.

This quasi-experimental study is the first study evaluating the efficacy of whole-body vs lesional application of permethrin for scabies treatment. We had already conducted a preliminary experimental study in 2014 which showed that lesional application of permethrin was as effective as wholebody application. ${ }^{5}$ Based on our study, we suggest that lesional permethrin combined with the correct method of personal hygiene habit can reduce the amount of permethrin used, leading to lower adverse effects. Twice-daily shower should be applied to both groups because proper hygiene is mandatory for any skin infections and infestation. The treatment is also more cost-effective because one tube of permethrin can be shared by several patients. However, the result of this study cannot be generalized. Larger studies with randomized controlled trial design are required.

\section{CONCLUSIONS}

In conclusion, the combination lesional application of $5 \%$ permethrin cream and proper hygiene habit showed advantages in treating scabies, such as similar efficacy with whole-body application, more cost-effective and less adverse events. Hence, lesional application of $5 \%$ permethrin cream can be considered to be implemented in treating scabies infestation, particularly in low socioeconomic settings and pediatric populations.

\section{CONFLICT OF INTERESTS}

All authors declared no conflict of interests

\section{REFERENCES}

1. Kashmir A. An endemic of scabies in Kahuta. The study shows a lack of awareness of scabies; mass treatment is needed [internet]. 2018 Available from: http://www.jpma.org.pk/ full_article_text.php? article_id=8363

2. Susilo RA. The association between the prevalence of scabies and the personal hygiene of the students in Islamic Boarding
Journal of Drug Delivery \& Therapeutics. 2021; 11(2):68-71 School X in East Jakarta [thesis]. Jakarta: Universitas Indonesia; 2014.

3. Sianturi I, Sungkar S. The relationship between hygienic practices towards scabies infestation in a boarding school of East Jakarta. eJKI. 2014; 2:357-41.

4. Romani L, Koroivueta J, Steer Ac, Kama M, Kaldor Jm, Wand H, et al. Scabies and impetigo prevalence and risk factors in Fiji. Plos Negl Trop Dis. 2015; 9:E452.

5. Sungkar S, Agustin T, Menaldi SL, Fuady H, Herqutanto, Angkasa $\mathrm{H}$, et al. Effectiveness of permethrin standard and modified methods in scabies treatment. Med J Indonesia. 2014; 23:93-8.

6. Manjhi PK, Sinha RI, Kumar M, Sinha KI. Comparative study of efficacy of oral ivermectin versus some topical antiscabies drugs in the treatment of scabies. J Clin Diagn Res. 2014; 8:1-4.

7. Sungkar S. Skabies. Jakarta: Badan Penerbit FKUI; 2016.

8. Karimkhani C, Colombara DV, Drucker AM, Norton SA, Hay R, Engelman D, et al. The global burden of scabies: a cross-sectional analysis from the Global Burden of Disease Study 2015. Lancet Infect Dis. 2017; 17:1247-54.

9. Kouotou EA, Nansseu JRN, Kouawa MK, Bissek ACZK. Prevalence and drivers of human scabies among children and adolescents living and studying in Cameroonian boarding schools. Parasite \& Vectors. 2016; 9:400.

10. Scabies: management [Internet]. UpToDate: Wolters Kluwer. $2018 . \quad$ Available from: https://www.uptodate.com/contents/scabies-management

11. Ranjkesh MR, Naghili B, Goldust M, Rezaee E. The efficacy of $5 \%$ permethrin vs oral ivermectin for the treatment of scabies. Annals of Parasitol. 2013; 59:189-94.

12. Rosumeck S, Nast A, Dressler C. Ivermectin and permethrin for treating scabies. Cochrane database of Syst Rev. 2018;4. DOI: 10.1002/14651858.CD012994

13. Karthikeyan K. Treatment of scabies: newer perspectives. Postgrad Med J. 2005;81:7-11

14. Chhaiya SB, Patel VJ, Dave JN, Mehta DS, Shah HA. Comparative efficacy and safety of topical permethrin, topical ivermectin, and oral ivermectin, in patients of uncomplicated scabies. IJDVL. 2012; 78:605-10.

15. Mila-Kierzenkowska C, Wozniak A, Krzyzynska-Malinowska E, Kaluzna L, Wesolowski R, Pocwiardowski W, et al. Comparative efficacy of topical permethrin, crotamiton, and sulfur ointment in treatment of scabies. J Arthropod-Borne Dis. 2017; 11:1-9.

16. Dressler C, Rosumeck S, Sunderkotter C, Werner RN, Nast A. The treatment of scabies: a systematic review of randomized controlled trial. Dtsch Arztebl Int. 2016; 113:757-62. 